\title{
Incidence of polyspermy in mouse eggs fertilized in vivo and in vitro after administration of progesterone and oestradiol
}

\author{
Lynn R. Fraser* and I. Maudlin† \\ Clinical Research Centre, Watford Road, Harrow, Middlesex, HA1 3UJ, U.K.
}

\begin{abstract}
Summary. Female mice, induced to superovulate, were injected subcutaneously with progesterone or oestradiol near the time when hCG was given. The incidence of polyspermy in first-cleavage embryos following mating or in-vitro fertilization was then determined. There were no detectable differences in the incidence or degree of polyspermy between treated and control in either the in-vitro or in-vivo groups, although the mean incidence of polyspermy was higher in vitro than in vivo. Furthermore, there was no detectable acceleration of egg transport after administration of either hormone.
\end{abstract}

\section{Introduction}

Recent studies of first-cleavage mouse embryos have reported consistently high levels of polyspermy when an in-vitro fertilization system has been used (Maudlin \& Fraser, 1977, 1978). The incidence of polyspermy has been shown to be affected both by the dose of PMSG used to stimulate the egg donors (Maudlin \& Fraser, 1977) and by the concentration of spermatozoa to which the eggs are exposed (Fraser \& Maudlin, 1978). Additionally, in-vivo studies carried out in the pig have suggested that relatively high progesterone levels, such as those in the luteal phase, may also produce an increased incidence of polyspermy (Hunter, 1967; Day \& Polge, 1968). Since eggs used for in-vitro fertilization are usually obtained following superovulation with exogenous hormones, the growth and development of more follicles than usual and their subsequent luteinization after ovulation might lead to elevated levels of progesterone or oestrogen and so affect the eggs and surrounding layers such that they become more permeable to spermatozoa. To test this possibility, oestradiol and progesterone were administered to mice induced to superovulate in order to determine whether the incidence of polyploidy, particularly polyspermy, is affected in eggs fertilized in vivo or in vitro.

\section{Materials and Methods}

Virgin 2-4-month-old (C57BL/10 × CBA) $\mathrm{F}_{1}$ females were induced to ovulate with 7.5 i.u. PMSG (Gestyl: Organon) and, approximately $48 \mathrm{~h}$ later, 5.0 i.u. hCG (Pregnyl: Organon). For fertilization in vivo, the hCG was administered $13 \mathrm{~h}$ before the estimated time of spontaneous ovulation and the females were caged overnight with mature TO males. Females which had vaginal plugs the following morning were kept until the afternoon when, approximately $14 \mathrm{~h}$ after ovulation, the fertilized, 1-cell embryos were recovered. The embryos were cultured overnight and chromosome preparations made as described previously (Maudlin \& Fraser, 1977).

* Present address: Department of Human Biology, Basic Medical Sciences Group, Chelsea College, Manresa Road, London, SW3 6LX, U.K.

† Present address: Nigerian Institute for Trypanosomiasis Research PMB 2077, Kaduna, Nigeria. 
For fertilization in vitro, females were killed $13 \mathrm{~h}$ after hCG and the unfertilized eggs were recovered. Epididymal sperm suspensions were prepared from 2-4-month-old TO males as described by Fraser \& Drury (1975), diluted to approximately $2 \times 10^{6} \mathrm{spermatozoa} / \mathrm{ml}$ and eggs were added. After a $6-\mathrm{h}$ incubation at $37^{\circ} \mathrm{C}$ in an atmosphere of $5 \% \mathrm{O}_{2}, 5 \% \mathrm{CO}_{2}, 90 \% \mathrm{~N}_{2}$, eggs were washed and cultured overnight in culture medium containing $10^{-5} \mathrm{~mm}$-vinblastine sulphate (Velbe: Lilly). The following morning embryos were processed for chromosome analysis (Maudlin \& Fraser, 1977).

The effects of progesterone and oestradiol were investigated. Some females received $1 \mathrm{mg}$ progesterone in $0.1 \mathrm{ml}$ arachis oil injected subcutaneously $1 \mathrm{~h}$ after the hCG injection; control animals received $0.1 \mathrm{ml}$ arachis oil s.c. Other females received $100 \mathrm{ng}$ oestradiol in $0.1 \mathrm{ml}$ arachis oil s.c. at the same time as the hCG, while controls received only oil.

\section{Results}

\section{Progesterone}

No significant effect of progesterone on the incidence of polyspermy was detected in vivo or in vitro (Table 1). Results from in-vivo matings are consistent with other in-vivo results (Maudlin \& Fraser, 1977, 1978) and did not differ significantly from one another. In addition, there was no evidence for accelerated egg transport in the treated females, all embryos being recovered from the ampullary end of the oviduct. Following in-vitro fertilization, the levels of polyspermy were higher than those obtained in vivo, but there was no significant difference between treated and control groups.

Table 1. The incidence of polyspermy in first-cleavage mouse embryos fertilized in vitro and in vivo after treatment of the egg donors with progesterone $(1 \mathrm{mg} 1 \mathrm{~h}$ after injection of hCG) or oestradiol (100 $\mathrm{ng}$ at the time of hCG injection)

\begin{tabular}{cccccccc}
\hline & \multicolumn{3}{c}{ Progesterone } & & \multicolumn{3}{c}{ Oestradiol } \\
\cline { 2 - 3 } \cline { 6 - 7 } & $\begin{array}{c}\text { No. of } \\
\text { exps }\end{array}$ & $\begin{array}{c}\text { No. of } \\
\text { embryos } \\
\text { examined }\end{array}$ & $\begin{array}{c}\text { No. of } \\
\text { polyspermic } \\
\text { embryos (\%) }\end{array}$ & & $\begin{array}{c}\text { No. of } \\
\text { exps }\end{array}$ & $\begin{array}{c}\text { No. of } \\
\text { embryos } \\
\text { examined }\end{array}$ & $\begin{array}{c}\text { No. of } \\
\text { polyspermic } \\
\text { embryos (\%) }\end{array}$ \\
\hline $\begin{array}{c}\text { In vitro } \\
\text { Treated }\end{array}$ & 5 & 276 & $19(6.9)$ & & 2 & 125 & $11(8.8)$ \\
$\begin{array}{c}\text { Control } \\
\text { In vivo }\end{array}$ & 5 & 279 & $26(9.3)$ & & 2 & 79 & $12(15 \cdot 2)$ \\
$\quad$ Treated & 7 & 185 & $1(0 \cdot 5)$ & 11 & 326 & $0(0)$ \\
Control & 5 & 127 & $2(1.6)$ & 7 & 153 & $0(0)$ \\
\hline
\end{tabular}

All the polyspermic embryos, both in vivo and in vitro, were dispermic triploids. In addition, 3 eggs in the in-vitro group had been fertilized by diploid spermatozoa and 3 digynic triploids were found, 2 in vivo and 1 in vitro. Most (80\%) of the in-vitro embryos could be scored for aneuploidy and the results indicated no significant differences between male and female complements or between embryos in the treated and untreated groups; the embryonic incidence of aneuploidy, calculated from the pooled data, was $1.9 \%$.

\section{Oestradiol}

There was no detectable effect of oestradiol on the incidence of polyploidy (Table 1) or on egg transport. None of the embryos recovered after mating from the treated or control groups 
were polyspermic. There were high levels of polyspermy in the embryos fertilized in vitro but the difference between the in-vitro groups was not significant.

Again, all polyspermic embryos were dispermic triploids. A further 3 had been fertilized by diploid spermatozoa. As in the progesterone experiments, most (95\%) of the in-vitro fertilized embryos could be scored for aneuploidy and again there were no significant differences between groups of embryos or the male- and female-derived complements; the overall embryonic incidence of aneuploidy was $1.7 \%$. In neither series of experiments was there any significant difference in the incidence of monosomic and trisomic embryos.

\section{Discussion}

Although the administration of exogenous progesterone shortly after hCG has been reported to cause a significant increase in the incidence of polyspermy in the pig ( $8 \%$ for controls versus $40 \%$ for treated; Day \& Polge, 1968), the results presented here give no indication of such an effect in the mouse, whether the eggs were fertilized in vivo or in vitro.

The effect on pig eggs was most pronounced when progesterone was administered 24-36 h before ovulation, the interval between hCG injection and ovulation being $40-42 \mathrm{~h}$ (Day \& Polge, 1968). Since the latter interval in the $F_{1}$ mice used in this study is approximately $13 \mathrm{~h}$ (Fraser, 1979), progesterone was administered shortly after hCG, and the relative time period before ovulation was therefore similar to that in the pig experiments. The hormone was not administered at the same absolute time before ovulation because this would have introduced the hormone during the follicular phase of development and hence into a very different hormonal milieu. Studies using the rabbit (Chang \& Hunt, 1968) and the hamster (Hunter, 1968) also failed to detect an increase in the incidence of polyspermy after administration of progesterone before ovulation, although neither study was strictly analogous to the present one. That of Chang \& Hunt (1968) involved use of delayed insemination, while Hunter (1968) noted a decrease in both the number of successful matings and the proportion of fertilized eggs in fertile matings; no such decrease was found in the present experiments.

Administration of oestradiol at similar times had no detectable effect on the incidence of polyspermy. While exogenous oestrogens have been reported to cause a "tube-locking" effect whereby early embryos are prevented from passing into the uterus (Burdick \& Pincus, 1935), the effect is obtained by hormone injections after ovulation and fertilization, i.e. at a time later than that studied in the present experiments. Oestradiol administration before ovulation did not appear to affect egg or sperm transport, since eggs were recovered from the ampulla and fertilization was normal. In both experimental series, the only detectable difference was the higher incidence of polyspermy in the eggs fertilized in vitro when compared with those fertilized in vivo. This difference has been consistently noted in earlier studies (Maudlin \& Fraser, 1977, 1978 ) and is, at least in part, a reflection of the relatively high sperm concentration used for invitro fertilization (Fraser \& Maudlin, 1978).

Although the administration of progesterone before ovulation apparently increases the rate of egg transport in both the pig (Day \& Polge, 1968) and rabbit (Chang, 1966), there was no evidence for this in the mouse. When progesterone was administered to sows shortly after hCG and the females killed $8 \mathrm{~h}$ after ovulation, $77 \%$ of the eggs were already in the uterus, compared with $0 \%$ in the untreated animals (Day \& Polge, 1968). In the present in-vivo experiments, female mice were killed approximately $14 \mathrm{~h}$ after ovulation, yet all eggs were still in the ampullary region of the oviduct. In the pig, accelerated egg transport could increase the probability of polyspermic fertilization by moving the eggs further down the oviduct before fertilization and hence into an area of higher sperm concentration than encountered under normal conditions. Hunter $(1973,1976)$ has demonstrated that the presence of large numbers of spermatozoa at fertilization leads to an increased incidence of polyspermy in the pig. When an 
aliquot of sperm suspension with a concentration of $1-3 \times 10^{8}$ spermatozoa $/ \mathrm{ml}$ was placed in the oviduct, $81 \%(343 / 421)$ of the eggs were polyspermic, with a mean of 28 spermatozoa/egg. Clearly the pig egg differs from the mouse egg when faced with high concentrations of spermatozoa, for when mouse eggs were fertilized in vitro in a high concentration of spermatozoa $\left(1 \times 10^{7} / \mathrm{ml}\right)$, none of the embryos showed excessive degrees of polyspermy. Almost all the polyploid embryos were dispermic triploids and the 2 sets of sperm-derived chromosomes were at similar stages of condensation, indicating fairly synchronous fertilization (Fraser \& Maudlin, 1978). The incidence of fertilization by diploid spermatozoa noted in these experiments is similar to those found in other studies (Maudlin \& Fraser, 1977, 1978). Even when sperm suspensions are preincubated $2 \mathrm{~h}$ to ensure capacitation before addition of eggs, the incidence and degree of polyspermy are consistent with those reported here (Fraser, 1979).

A further possibility for the observed effect of progesterone in the pig is an alteration in the normal block to polyspermy. If such an effect also occurred in the mouse, the in-vitro system which exposes eggs to higher sperm concentrations than those usually found in vivo should permit detection of such changes, but none was noted. There was neither an increase in the incidence of polyspermy nor an increase in the number of spermatozoa which successfully penetrated the eggs in the treated group; all polyspermic embryos were only dispermic.

From these results it would appear that the administration of exogenous progesterone or oestradiol to mice around the time of an ovulation-inducing injection of hCG does not result in an increased incidence of polyspermy, an increased degree of polyspermy (>dispermy) or accelerated egg transport.

\section{References}

Burdick, H.O. \& Pincus, G. (1935) The effect of oestrin injections upon the developing ova of mice and rabbits. Am. J. Physiol. 111, 201-208.

Chang, M.C. (1966) Effects of oral administration of medroxyprogesterone acetate and ethinyl estradiol on transportation and development of rabbit eggs. Endocrinology 79, 939-948.

Chang, M.C. \& Hunt, D.M. (1968) Attempts to induce polyspermy in the rabbit by delayed insemination and treatment with progesterone. J. exp. Zool. 167, 419-426.

Day, B.N. \& Polge, C. (1968) Effects of progesterone on fertilization and egg transport in the pig. J. Reprod. Fert. 17, 227-230.

Fraser, L.R. (1979) Rate of fertilization in vitro and subsequent nuclear development as a function of the post-ovulatory age of the mouse egg. J. Reprod. Fert. $55,153-160$.

Fraser, L.R. \& Drury, L.M. (1975) The relationship between sperm concentration and fertilization in vitro of mouse eggs. Biol. Reprod. 13, 513-518.

Fraser, L.R. \& Maudlin, I. (1978) Relationship between sperm concentration and the incidence of poly- spermy in mouse embryos fertilized in vitro. $J$. Reprod. Fert. 52, 103-106.

Hunter, R.H.F. (1967) Polyspermic fertilization in pigs during the luteal phase of the oestrous cycle. J. exp. Zool. 165, 451-460.

Hunter, R.H.F. (1968) Effect of progesterone on fertilization in the golden hamster. J. Reprod. Fert. 16, 499-502.

Hunter, R.H.F. (1973) Polyspermic fertilization in pigs after tubal deposition of excessive numbers of spermatozoa. J. exp. Zool. 183, 57-69.

Hunter, R.H.F. (1976) Sperm-egg interactions in the pig: monospermy, extensive polyspermy, and the formation of chromatin aggregates. J. Anat. 122, 4359.

Maudlin, I. \& Fraser, L.R. (1977) The effect of PMSG dose on the incidence of chromosomal anomalies in mouse embryos fertilized in vitro. $J$. Reprod. Fert. $50,275-280$.

Maudlin, I. \& Fraser, L.R. (1978) The effect of sperm and egg genotype on the incidence of chromosomal anomalies in mouse embryos fertilized in vitro. $J$. Reprod. Fert. 52, 107-112.

Received 6 July 1978 